\title{
Análise de espessuras de lajes de pontes em balanço
}

\author{
Analysis of thickness in deck slab overhangs \\ Análisis de espesor em voladizo de los puentes
}

Recebido: 25/06/2021 | Revisado: 01/06/2021 | Aceito: 07/07/2021 | Publicado: 09/07/2021

\author{
Luan Bastos Correia \\ ORCID: https://orcid.org/0000-0003-0660-8845 \\ Universidade Federal Fluminense, Brasil \\ E-mail: luanbastos@id.uff.br \\ Luiz Carlos Mendes \\ ORCID: https://orcid.org/0000-0003-1747-5179 \\ Universidade Federal Fluminense, Brasil \\ E-mail: 1carlos@predialnet.com.br
}

\begin{abstract}
Resumo
As pontes rodoviárias de concreto armado devem ser construídas levando em consideração a ação de cargas permanentes e variáveis, como também as ações dinâmicas provenientes do tráfego de veículos. O advento da globalização e consequentemente a expansão do fluxo de veículos, principalmente os de grande porte, são uns dos fatores de extrema importância a serem avaliados no processo de montagem e dimensionamento de superestruturas, pois estão inerentes ao surgimento de momentos fletores transversais na laje da ponte. A correta consideração desses aspectos para análise estrutural de uma ponte motivou o desenvolvimento desse estudo, para avaliar os esforços despertados no elemento estrutural responsável por suportar as cargas de tráfego, as lajes. Intrínseco a esse estudo, é analisada a relação da variação de espessuras das lajes em balanço (cantilever) com a intensidade dos momentos transversais despertados na região de influência do tabuleiro. O estudo aborda o modelo analítico desenvolvido por Bakht e Jaeger (1985), realizando uma inspeção dos momentos fletores despertados na laje em balanço, a partir da aplicação de cargas concentradas sobre a superfície do cantilever, bem como a variação de suas posições e das espessuras da superestrutura. A pesquisa é elaborada com o auxílio do programa computacional Microsoft Excel. As conclusões desse trabalho versam a correta análise dos esforços despertados em lajes de pontes em balanço, bem como os benefícios proporcionados pela variação de espessuras do tabuleiro e a introdução de vigas de bordo na estrutura, proporcionando uma maior eficiência de redução dos momentos transversais despertados no tabuleiro.
\end{abstract}

Palavras-chave: Pontes; Laje em balanço; Carga; Espessura; Momentos transversais.

\begin{abstract}
The reinforced concrete highway bridges must be built taking into account the action of permanent and variable loads, as well as the dynamic actions from vehicle traffic. The advent of globalization and consequently the expansion of vehicle flow, especially large vehicles, are some of the factors of extreme importance to be evaluated in the process of assembly and design of superstructures, because they are inherent to the emergence of transverse bending moments in the bridge slab. The correct consideration of these aspects for the structural analysis of a bridge motivated the development of this study to evaluate the stresses aroused in the structural element responsible for supporting traffic loads, the slabs. Intrinsic to this study is the analysis of the relationship between the variation in thickness of the cantilever slabs and the intensity of the transverse moments aroused in the region of influence of the deck. The study approaches the analytical model developed by Bakht and Jaeger (1985), performing an inspection of the bending moments aroused in the cantilever slab, from the application of concentrated loads on the cantilever surface, as well as the variation of their positions and the thicknesses of the superstructure. The research is carried out with the aid of the Microsoft Excel computer program. The conclusions of this work deal with the correct analysis of the efforts aroused in cantilever bridge slabs, as well as the benefits provided by varying the thickness of the deck and the introduction of edge beams in the structure, providing greater efficiency in reducing the transverse moments aroused in the deck.
\end{abstract}

Keywords: Bridge; Deck slab overhangs; Load; Thickness; Transverse moments.

\section{Resumen}

Los puentes de carretera de hormigón armado deben construirse teniendo en cuenta la acción de las cargas permanentes y variables, así como las acciones dinámicas del tráfico de vehículos. El advenimiento de la globalización y la consiguiente expansión del flujo de vehículos, especialmente los de gran tamaño, son algunos de los factores extremadamente importantes que deben evaluarse en el proceso de montaje y diseño de las superestructuras, ya que son inherentes a la aparición de momentos flectores transversales en la losa del puente. La correcta consideración de estos aspectos para el análisis estructural de un puente motivó el desarrollo de este estudio para evaluar las tensiones suscitadas en el elemento estructural encargado de soportar las cargas de tráfico, las losas. Es 
intrínseco a este estudio el análisis de la relación entre la variación del espesor de las losas en voladizo y la intensidad de los momentos transversales en la región de influencia del tablero. El estudio aborda el modelo analítico desarrollado por Bakht y Jaeger (1985), realizando el cálculo de los momentos fletores despertados en la laja en equilibrio, a partir de la aplicación de cargas concentradas sobre la superficie del voladizo, así como la variación de sus posiciones y las espesuras de la superestructura. La investigación se lleva a cabo con la ayuda del programa informático Microsoft Excel. Las conclusiones de este trabajo abordan el correcto análisis de los esfuerzos suscitados en las losas de los puentes en voladizo, así como los beneficios que aporta la variación del espesor del tablero y la introducción de vigas de borde en la estructura, proporcionando una mayor eficacia en la reducción de los momentos transversales suscitados en el tablero.

Palabras clave: Puentes; Voladizo; Carga; Espesor; Momentos transversales.

\section{Introdução}

O processo de construção de pontes está presente em toda trajetória de evolução e desenvolvimento do homem e da sociedade, representando a superação de desafios, obstáculos e solução de problemas impostos pela natureza e pelo crescimento das cidades com a globalização.

Segundo Marchetti (2018) pontes são obras destinadas a vencer obstáculos e permitir a continuidade de vias de comunicação.

Desde a história antiga é possível identificar a utilização de pontes, também chamadas de obras de artes especiais, como grandes marcos de superação e engenharia dos povos antigos e que resistem até hoje, passados milhares de anos, como os famosos aquedutos romanos, também utilizados como via de acesso de povos na superação de obstáculos naturais.

$\mathrm{O}$ advento da globalização acarretou o crescimento contínuo do fluxo de pessoas e veículos pelo mundo e por consequência a necessidade de construção de vias de acesso e pontes capazes de atenderem a demanda com eficiência e segurança esse crescimento exponencial de movimentação e solicitação nas superestruturas projetadas nas cidades.

Quando tratamos de pontes e mais especificamente de suas lajes ou tabuleiros é imprescindível que seja analisado e estudado minuciosamente as ações que ocorrem nos chamados balanços da laje (cantilever), os quais apresentam quesitos e pontos de análise que devem ser verificados com bastante atenção e responsabilidade durante o processo de dimensionamento.

Bakht e Jaeger (1985) explicam que a aplicação de cargas pontuais em determinados pontos do balando de uma laje de ponte, pode gerar a superestimação de momentos transversais que não são considerados durante o processo de dimensionamento. Esses momentos correlacionam-se intimamente com questões de segurança e estabilidade do elemento estrutural, uma vez que o surgimento de fissuras na direção longitudinal compromete a rigidez da peça e consequentemente a resistência à flexão da mesma.

Motivado pela necessidade de contribuição acadêmica e científica para o estudo pouco abordado no Brasil, este trabalho busca apresentar uma análise específica desses problemas encontrados em lajes de pontes em balanço, os quais estão associados a variação de espessuras do tabuleiro, conforme apresentado por Bakht e Jaeger (1985) em seus métodos de análises com as equações propostas.

O estudo aqui apresentado é pautado no modelo matemático desenvolvido e atualizado por Bakht e Mufti (2015) para análise de pontes com lajes em balanço, também chamadas de cantilever, onde é realizada a investigação dos momentos fletores transversais e sua relação com a razão de espessuras das lajes, bem como o posicionamento de cargas concentradas sobre o tabuleiro e a utilização de vigas de borda com finalidade de enrijecimento da estrutura.

\section{Metodologia}

Para elaboração da pesquisa foi utilizado o Estudo de casos, através do método qualitativo, pois este auxilia da melhor forma a compreensão de fenômenos individuais estudados. 
A pesquisa foi embasada pelas normas brasileiras NBR 7187 (ABNT, 2003) e NBR 7188 (ABNT, 2013), em conjunto com o método de análise de lajes de pontes em balanço apresentado por Bakht e Jaeger (1985) e atualizado por Bakht e Mufti (2015).

Para formulação dos cálculos do modelo matemático estudado, foi utilizado o software Excel para dinamização de cálculos e gráficos. Os dados de entrada do estudo de casos analisados são apresentados no capítulo 5 deste trabalho.

A organização do estudo realizado consiste na análise de diferentes modelos hipotéticos de lajes de pontes em balanço, também chamados de cantilever, com a variação das razões de espessuras da estrutura em balanço, bem como a variação de aplicação de carga concentrada aplicada sobre o tabuleiro.

A partir dos resultados obtidos, são apresentadas análises e discussões inferidas no estudo de casos e por fim a apresentação da conclusão pertinente ao tema apresentado.

\section{Referencial Teórico}

\subsection{Histórico}

Mendes (2003) classifica pontes como obras de artes, cuja finalidade é proporcionar o acesso, superando obstáculos naturais como cursos d'água, baías, vales profundos ou até mesmo dificuldades criadas pelo homem nos centros urbanos ou em vias expressas.

O processo de construção de pontes está presente desde a antiguidade com os povos primitivos, na elaboração de pontes de cordas, pedras, madeira, na forma de vigas escoradas, vigas armadas simples (Leonhardt, 1979).

É importante salientar que desde a história antiga, antes de Cristo, as construções de pontes sempre foram realizadas com características artísticas, onde se podem citar os romanos que utilizavam pedras para vencer os obstáculos e esculpir verdadeiras obras de artes, como arcos e abóbodas, muitas vezes utilizados para condução de canalizações de água, aquedutos. Figura 1 apresenta a umas das mais belas construções antigas de pontes no mundo.

Com o advento da Idade Média e Moderna, esses processos construtivos de pontes foram ganhando novas tendências, formatos e modelos, onde em meio ao desenvolvimento e avanço tecnológico, o surgimento de novos materiais também contribuiu significativamente para que novas tendências e tipos de pontes fossem apresentados e aderidos pelos povos.

Vale mencionar o surgimento do concreto protendido, por volta da metade do século XX, quando essa técnica construtiva conquistou o mundo da construção civil, com larga utilização na edificação de pontes, principalmente vigas protendidas que apresentam a eficácia de vencer grandes vãos.

\subsection{Elementos constituintes da ponte}

Do ponto de vista funcional, as pontes podem ser divididas basicamente em três partes principais: superestrutura, mesoestrutura e infraestrutura.

Superestrutura é o elemento suporte imediato do estrado, responsável por receber diretamente as cargas provenientes do tráfego, ou seja, a parte útil da obra. A superestrutura é formada pelas lajes, vigas principais (longarinas), transversinas, cortinas, chanfros, consoles, dentes etc.

Mesoestrutura é o elemento estrutural responsável por receber os esforços provenientes da superestrutura (peso próprio e cargas de tráfego) e transmiti-los a infraestrutura, no topo do pilar, juntamente com outros esforços recebidos pela ponte de outras forças solicitantes, como a pressão da água em movimento e do vento em diversas direções. A mesoestrutura é composta pelos aparelhos de apoios, pilares e vigas de contraventamento de pilares.

Infraestrutura ou fundação é o elemento estrutural da ponte responsável por transmitir os todos os esforços recebidos desde a susperestrutura para o terreno de implantação da obra, rocha ou solo. A infraestrutura é constituída pelos blocos, 
estacas, sapatas, tubulões, estaqueamentos, caixões, além das peças de ligações dos seus diversos elementos, como as vigas de enrijecimento dos blocos.

\section{Lajes de Pontes}

As lajes de pontes possuem como finalidade principal o suporte dos carregamentos verticais provenientes dos veículos com o intuito de transmiti-los à superestrutura, para que assim as cargas sigam seu fluxo de dispersão até o solo, passando por todas as etapas do sistema estrutural, como foi abordado anteriormente.

As características das lajes de pontes são semelhantes às lajes dos edifícios de modo geral, diferenciando-se principalmente pelas peculiaridades do carregamento atuante, uma vez que o carregamento predominante é devido cargas concentradas ou distribuídas em determinadas áreas. Vale ressaltar também que a estrutura sofre a ação de cargas móveis, que atuam em diversas posições, ocasionando efeitos dinâmicos, os quais não podem ser desprezados. Esses efeitos são considerados na análise e processo de dimensionamento através dos coeficientes de impacto (Cunha \& Souza , 1994) .

O tabuleiro também irá atuar como um diafragma horizontal, que é capaz de transferir as cargas laterais, tais como cargas de vento ou sísmicas, para os suportes.

\subsection{Análise de lajes em balanço (cantilever)}

A variação de espessuras de lajes de pontes é uma técnica utilizada nos projetos estruturais com a finalidade de proporcionar melhor efeito estético, reduzir o peso próprio da construção e gerar uma utilização mais eficiente do concreto e da armadura (Reissen \& Hegger, 2015).

Bakht (1981) explica que saliências em pontes, foram tradicionalmente idealizadas como lajes em balanço, também chamadas de cantilever. Essas estruturas são projetadas em forma de espessura cônica ao longo da laje, onde diminuem a partir da raiz (início do balanço) até o bordo livre, podendo ser finalizada com uma viga de borda, conforme ilustra Figura 1.

Figura 1: Balanço de ponte idealizada como laje cantilever, submetida à ação de uma carga concentrada de um veículo aplicada a uma determinada distância da raiz do balanço.

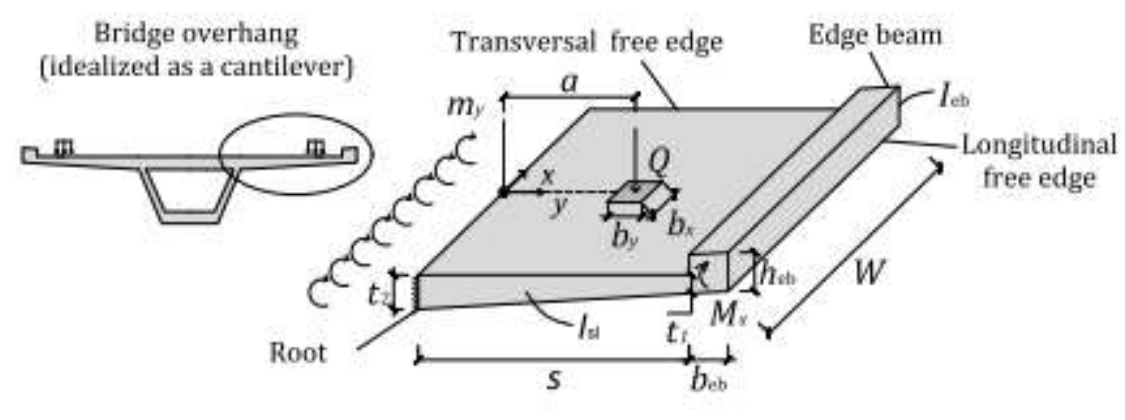

Fonte: Munoz (2020).

O estudo do comportamento da laje em balanço é de grande relevância, onde faz-se necessário uma correta análise dos momentos fletores transversais despertados na direção longitudinal, os quais estão associados ao surgimento de fissuras o longo da direção longitudinal do tabuleiro e por consequência comprometem a rigidez flexional da peça.

\subsection{Mecânica do comportamento de uma laje em balanço (cantilever)}

A compreensão do comportamento e da forma como as forças são transmitidas através da estrutura é fundamental para uma análise eficiente e segura do comportamento estrutural de uma construção, por parte de um engenheiro, e não somente a 
análise estrutural, mas também a verificação dos valores obtidos através de computadores, para que esses estejam dentro dos limites esperados (Bakht \& Mufti, 2015). Por isso a necessidade de compreensão do comportamento da laje de pontes em balanço, submetida à ação de uma carga concentrada

Figura 2: Distribuição das intensidades de momentos transversais em lajes de pontes em balanço.

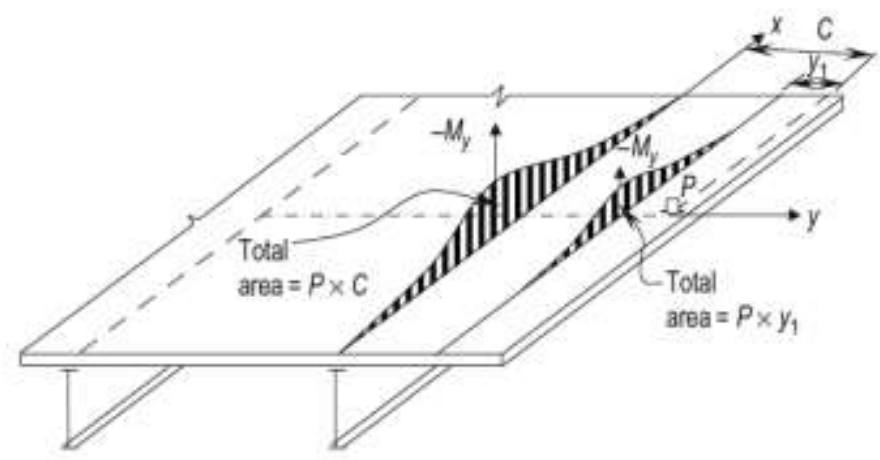

Fonte: Bakht e Mufti (2015).

A Figura 2 esboça o comportamento de uma laje de ponte em balanço quando submetida à ação de uma carga concentrada, com o surgimento de momentos ao longo da seção com intervalos de intensidades diferentes.

De acordo com a figura $\mathrm{n}^{\circ} 6$, o momento total na raiz é expresso por $P C$, onde $P$ representa a carga aplicada e $C$ a distância transversal da raiz. $\mathrm{O}$ momento total da laje em balanço e a área total sob a curva $\mathrm{M}_{\mathrm{y}}$ na seção longitudinal não são afetados por outros fatores, além da magnitude da carga e a distância da seção considerada.

Existem quatro fatores que interferem na distribuição de momentos $\mathrm{M}_{\mathrm{y}}$ ao longo da seção longitudinal, e consequentemente também influencia a intensidade do momento de pico na laje em balanço (cantilever). Os fatores são:

- Endurecimento da borda;

- Taxa de Espessura da laje - $\mathrm{O}$ efeito da relação da taxa de espessura de lajes com a intensidade de momentos devido à distribuição de $\mathrm{M}_{\mathrm{y}}$, pode ser entendida considerando o caso improvável em que a espessura da laje na borda é maior do que na raiz do cantilever (balanço), ou seja $\mathrm{t}_{2} / \mathrm{t}_{1}$ é maior que 1,0. Pode ser observado que a seção transversal de tal laje é semelhante à seção transversal de uma laje uniforme, com seu bordo enrijecido, ou seja, com a borda reforçada. Com análise comprovada através de estudos, verifica-se que o aumento do valor da razão $t_{2} / t_{1}$ ocasiona uma redução do valor de pico de $\mathrm{M}_{\mathrm{y}}$. $\mathrm{O}$ encadeamento dedutivo desta observação é que o aumento da intensidade de pico do momento $\mathrm{M}_{\mathrm{y}}$ está relacionado com a redução da relação $\mathrm{t}_{2} / \mathrm{t}_{1}$. Estima-se que o máximo valor de $\mathrm{M}_{\mathrm{y}}$ devido à ação de uma carga concentrada na ponta de uma laje em balanço totalmente fixa com $t_{2} / t_{1}=0,33$, apresenta um aumento de aproximadamente $37 \%$ em relação a uma laje com $\mathrm{t}_{2} / \mathrm{t}_{1}=1,0$.

- Restrição contra deflexão;

- Restrição contra rotação.

\subsection{Método para uma laje em balanço infinita não enrijecida}

$\mathrm{O}$ efeito de uma carga concentrada em uma laje em balanço torna-se insignificante a partir de uma distância superior a "2a" na direção longitudinal da placa, sendo "a" igual à largura do balanço. 
Os momentos transversais por unidade de comprimento $\mathrm{M}_{\mathrm{yc}}$, devidos ao carregamento $\mathrm{P}$ em uma laje em balanço infinita, que varia de espessura linearmente na direção transversal, são obtidos pela expressão:

$$
\mathrm{M}_{\mathrm{yc}}=\frac{\mathrm{P}}{\pi} \cdot \mathrm{A}^{s} \cdot\left[\frac{1}{\cosh \left(\frac{A^{x} \cdot \mathrm{x}}{c-y}\right)}\right](3.1)
$$

Onde A' é um coeficiente que depende da carga das posições da carga, da localização do ponto de referência em relação a raiz do balanço, e da relação da espessura da laje, que é a relação entre a espessura no engaste e aquela no bordo livre longitudinal.

Os valores de A' podem ser obtidos através dos gráficos apresentados por Bakht e Holland (1976), para diferentes locais de carga e pontos de referência em laje cantilever de espessura linearmente onde se encontram relações de espessuras de $\mathrm{t}_{2} / \mathrm{t}_{1}$ iguais a 1,2 e 3 , e, estes para valores intermediários, onde $\mathrm{t}_{1}$ e $\mathrm{t}_{2}$ são espessuras da laje na raiz e na ponta do balanço, permitindo-se uso de interpolação linear.

São definidos também:

$\mathrm{c}=$ distância do ponto de aplicação da carga ao bordo engastado;

$\mathrm{a}=$ comprimento transversal da laje em balanço ;

$\mathrm{y}=$ ponto de referência onde se deseja determinar o momento fletor $\mathrm{M}_{\mathrm{yc}}$;

$\mathrm{x}=$ distância longitudinal do ponto de referência até o ponto de aplicação da carga P ;

$\mathrm{t}_{1}=$ menor espessura da laje em balanço ;

$\mathrm{t}_{2}=$ maior espessura da laje em balanço ;

A intensidade do momento $\mathrm{M}_{\mathrm{yc}}$ é máxima quando a carga concentrada está localizada o mais distante possível do engaste.

Bakht e Jaeger (1990) apresentaram uma equação algébrica, onde mostram que o cosseno hiperbólico (cosh) da equação 3.1, pode ser substituído por uma função algébrica, de modo que passe a apresentar o seguinte formato:

$$
\mathrm{M}_{y}=-\frac{2 \mathrm{P}}{\pi} \cdot B \cdot\left[\frac{(\mathrm{C}-\mathrm{y})^{4}}{\left[(\mathrm{C}-\mathrm{y})^{2}+(\mathrm{Bx})^{2}\right]^{2}}\right]
$$

Onde

$$
\mathrm{B}=\frac{\mathrm{A}^{\prime}}{2}(3.3)
$$

\subsection{Método para uma laje em balanço semi-infinita e não enrijecida}

Método é aplicado para trechos da laje que se situam nas proximidades dos bordos transversais livres. Neste caso, são desconsiderados os trechos infinitos da laje em balanço infinita não enrijecida.

Bakht et al. (1979) mostra que o momento $\mathrm{M}_{\mathrm{yc}}$ despertado na raiz do balanço de uma laje, ou seja, momento no engaste da laje em virtude da carga concentrada perto de uma borda livre transversal é definida por:

$$
\mathrm{M}_{\mathrm{yc}}=\frac{\mathrm{P}}{\pi} \cdot A^{s} \cdot\left[\frac{1}{\cosh \left(\frac{A^{r} \cdot \mathrm{x}}{c}\right)}+\mathrm{B}^{x} \cdot \mathrm{e}^{-\frac{K x_{\mathrm{b}}}{\mathrm{g}}}\right]
$$


Os valores de K são definidos por:

$$
\mathrm{K}=\frac{\mathrm{a}}{\mathrm{c}} \cdot \frac{\mathrm{A}^{\mathrm{x}} \cdot \mathrm{B}^{\prime}}{2} \cdot\left[\frac{1}{\operatorname{arctg}\left(\mathrm{e}^{-\frac{A^{\prime} X_{2}}{\mathrm{c}}}\right)}\right](3.5)
$$

Os valores de A' e B' são obtidos através dos gráficos apresentados por Bakht (1979), para as mais variadas relações $\mathrm{t}_{2} / \mathrm{t}_{1}$ e $\mathrm{y} / \mathrm{a}$

\subsection{Método para uma laje em balanço infinita de bordo enrijecido}

A maioria das lajes em balanço possui vigas de bordos invertidas com o objetivo de enrijecer o bordo livre e geralmente são monolíticas com as lajes a que se ligam. Estas vigas melhoram consideravelmente a distribuição das cargas ao longo da laje.

O tratamento é quase similar ao das lajes não enrijecidas, porém a única diferença é o parâmetro A' obtido dos gráficos da figura 12, e depende da rigidez flexional da viga de bordo, da rigidez flexional da laje em balanço e as espessuras envolvidas. O valor de A' agora também depende da razão entre a rigidez à flexão da viga de bordo para a rigidez total da laje em balanço em torno do seu próprio eixo neutro.

Os momentos nos balanços transversais devido a uma carga concentrada são obtidos por meio da equação eq. (3.10), em que o valor do coeficiente A' é obtido a partir do gráfico apresentado por Bakht (1976). O valor de A' depende da relação da espessura da laje, e relação das rigidezes viga de bordo e da laje em balanço, e as posições de cargas e pontos de referência. O método é aplicável apenas quando y é menor do que c.

Bakht (1981) apresentou alguns outros gráficos para cálculo de diferentes calores de A', quando as lajes em balanço (cantilever) apresentam reforço estrutural em suas bordas. A obtenção de valores de A' através desses gráficos se dão com a relação do momento de inércia da borda seção transversal da viga $\left(I_{s}\right)$ e o momento de inércia da laje em balanço (cantilever) ( $\left.\mathrm{I}_{\mathrm{b}}\right)$ também da seção transversal.

Os novos valores de A' obtidos nos gráficos também dependem da variação da espessura da laje em balanço (cantilever) e da posição relativa da carga (y/a), porém, esses gráficos foram feitos apenas para cantilever com enrijercedores (meio-fio) localizados na borda do balanço e com restrição rotacional infinita em seu apoio longitudinal.

As rigidezes flexionais da laje e da viga são definidas pelas expressões 3.4 e 3.5 respectivamente:

$$
\begin{aligned}
& I_{s}=\frac{a}{48} \cdot\left(t_{2}^{a}+t_{2}^{2} \cdot t_{1}+t_{2} \cdot t_{1}^{2}+t_{1}^{a}\right)=\frac{a}{48} \cdot \frac{t_{2}^{4}-t_{1}^{4}}{t_{2}-t_{1}} \\
& I_{b}=\frac{b \cdot h^{a}}{12}(3.5)
\end{aligned}
$$

$\mathrm{I}_{\mathrm{s}}=$ momento de inércia da área da laje em balanço com variação de espessura em relação ao eixo médio da seção transversal;

$\mathrm{I}_{\mathrm{b}}=$ momento de inércia da área da viga de bordo em relação ao eixo médio da seção transversal;

$\mathrm{b}=$ espessura da viga de bordo;

$\mathrm{h}=$ altura da viga de bordo;

$\mathrm{t}_{2}=$ maior espessura da laje em balanço;

$\mathrm{t}_{1}=$ menor espessura da laje em balanço; 


\subsection{Método para uma laje em balanço semi-infinita de bordo enrijecido}

Observa-se no procedimento numérico que a redução dos momentos provenientes das cargas concentradas ocorre devido ao fato de bordo enrijecido distribuir os efeitos da carga mais efetivamente na direção longitudinal da laje. Se a laje não enrijecida, os momentos no bordo se tornam altamente concentrados e localizados.

O projeto pode tomar um tratamento mais preciso quando se considera um comprimento " $2 \mathrm{a}$ " da seção transversal da laje medido a partir de um bordo transversal livre como sendo um trecho semi-infinito, como mostrado na figura $\mathrm{n}^{\circ}$ 7. Quando a laje é enrijecida longitudinalmente, os efeitos locais são mais distribuídos na direção longitudinal. O método é similar à laje semi-infinita não enrijecida descrito anteriormente. A única diferença é que os coeficientes A' e B' vão depender das relações entre os momentos de inércia de viga e laje $\mathrm{I}_{\mathrm{b}} / \mathrm{I}_{\mathrm{s}}$. Os valores de A' e B' são obtidos com auxílio dos gráficos apresentados por Bakht (1976).

As expressões empregadas para determinação do momento fletor na laje por carga concentrada são as mesmas que as equações anteriormente apresentadas.

No tratamento da laje não enrijecida os valores de $\mathrm{M}_{\mathrm{yc}}$ são obtidos apenas nos pontos do bordo engastado da laje em balanço.

\section{Estudo de Casos}

\subsection{Dados de Entrada}

Com o auxílio do Microsoft Excel foram elaboradas diversas planilhas, programadas para calcular e assim poder realizar a análise dos momentos fletores transversais despertados nos bordos engastados de lajes em balanço (cantilever) de pontes rodoviárias em concreto armado, sujeitas a ação de carga concentrada de roda $\mathrm{P}=75 \mathrm{KN}$, conforme trem-tipo brasileiro de classe 45 para pontes rodoviárias.

O presente estudo apresenta a análise de casos de lajes de pontes infinitas e semi-infinitas em balanço, com e sem enrijecimento do bordo livre, correlacionando a ação da aplicação de cargas concentradas em diversas posições ao longo do comprimento transversal da laje em balanço $\mathrm{a}=2 \mathrm{~m}$.

O eixo de referência foi tomado com posição em $y=0$, no alinhamento do bordo engastado, e a carga $\mathrm{P}$ concentrada foi locada no ponto referencial de $\mathrm{x}=0$.

A pesquisa foi realizada para três relações distintas de espessura de lajes, como sendo t2/t1 =1, 2 e 3 , conforme ilustra Figura 3. 
Figura 3: Razões t2/t1 de espessuras das lajes em balanço.
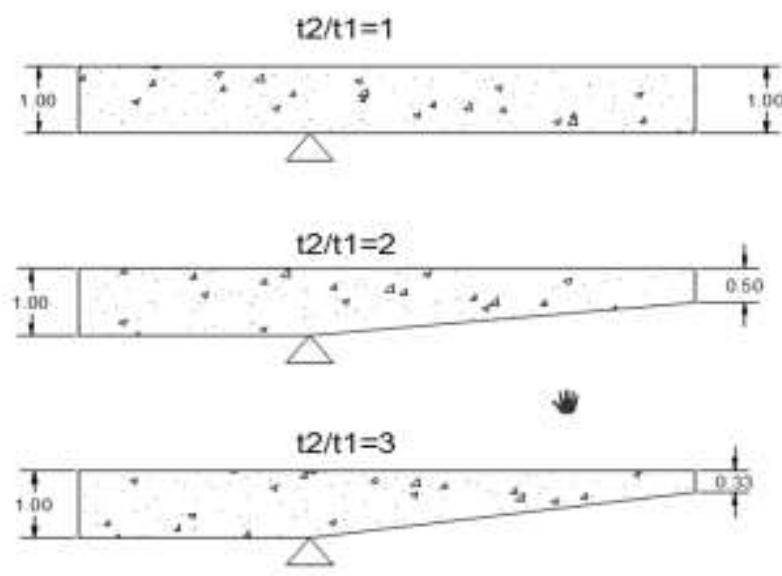

Fonte: Autores.

A partir das equações apresentadas por Bakht e Jaeger (1985), foi realizada a análise da intensidade de momentos fletores na raiz do balanço (bordo engastado), também chamados de momentos transversais, através da aplicação de cargas concentradas em diversos pontos da direção transversal da laje em balanço.

Convencionalmente foram utilizadas as seguintes nomenclaturas para melhor compreensão de cada caso analisado na pesquisa:

CASO 1 - MÉTODO PARA UMA LAJE EM BALANÇO INFINITA NÃO ENRIJECIDA;

CASO 2 - MÉTODO PARA UMA LAJE EM BALANÇO SEMI-INFINITA NÃO ENRIJECIDA;

CASO 3 - MÉTODO PARA UMA LAJE EM BALANÇO INFINITA ENRIJECIDA

CASO 4 - MÉTODO PARA UMA LAJE EM BALANÇO INFINITA ENRIJECIDA

\subsection{Análise dos resultados}

Figura 4: Momento de engastamento laje infinita (CASO 1).

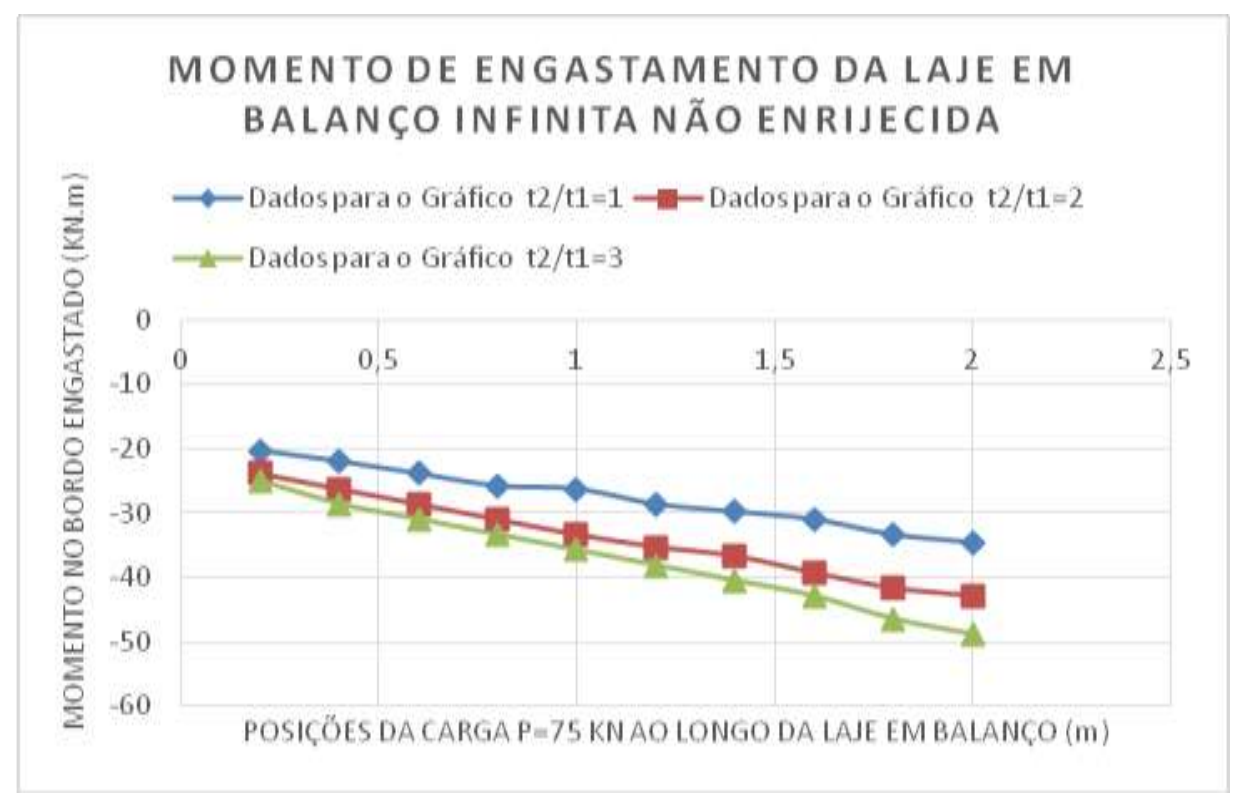

Fonte: Autores. 
$\mathrm{Na}$ análise dos resultados obtidos a partir do CASO 1 (MÉTODO PARA UMA LAJE EM BALANÇO INFINITA NÃO ENRIJECIDA) observa-se que os momentos transversais despertados na laje em balanço infinita sem enrijecimento tendem a uma maior intensidade de pico à medida que aumentamos a distância de aplicação da carga concentrada em relação à direção transversal, conforme se pode verificar no gráfico ilustrado da Figura 4. A intensidade desses momentos é despertada na direção longitudinal do balanço e está intimamente ligada ao surgimento de fissuras longitudinais, as quais ocasionam uma redução da rigidez flexional da estrutura.

Figura 5: Momento de engastamento laje semi-infinita (CASO2).

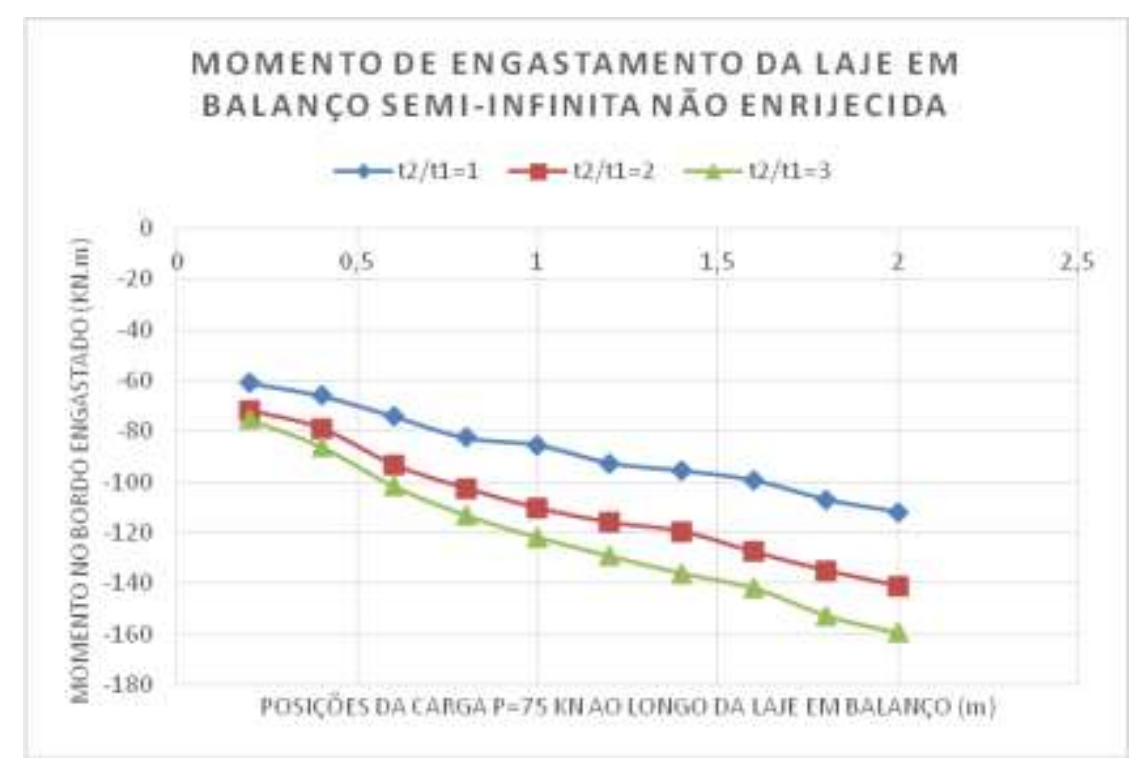

Fonte: Autores.

$\mathrm{Na}$ análise dos valores obtidos no CASO 2 (MÉTODO PARA UMA LAJE EM BALANÇO SEMI-INFINITA NÃO ENRIJECIDA) observa-se que os momentos despertados no engaste, a partir da aplicação de uma carga concentrada são bem maiores quando comparados com a intensidade de momentos de pico nas lajes infinitas sem enrijecimento.

Com base no gráfico da Figura 5 verifica-se que a variação de espessuras das lajes de pontes em balanço, representadas pelas razões de $\mathrm{t}_{2} / \mathrm{t}_{1}$ apresentam características distintas, à medida que a razão entre as espessuras diminui. A análise permite inferir que a variação de espessuras proporciona um aumento na intensidade dos picos de momentos fletores despertados na raiz do balanço, ou seja, espessuras iguais, com razão $t_{2} / t_{1}=1$ apresentam melhor desempenham na distribuição da carga concentrada ao longo do balanço e consequentemente apresentam momentos menores, quando comparados com espessuras distintas entre a laje e o enrijecimento. 
Figura 6: Momento de engastamento laje infinita enrijecida (CASO 3).

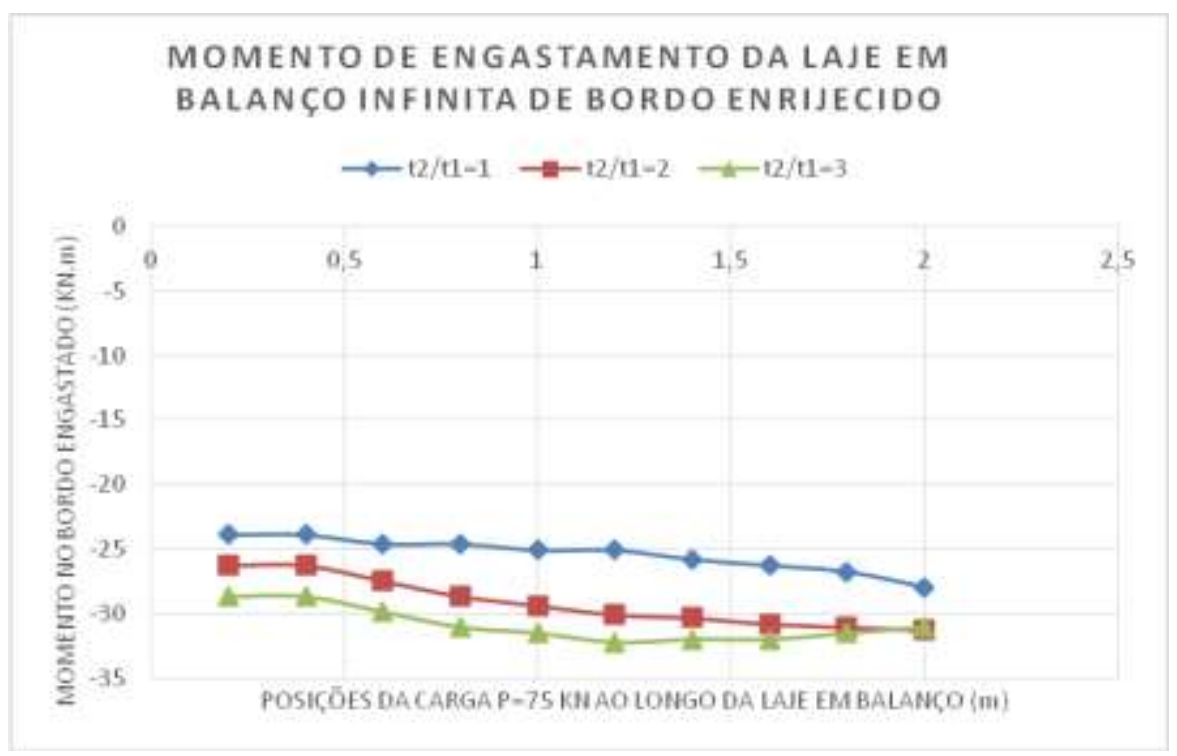

Fonte: Autores.

A análise do CASO 3 (MÉTODO PARA UMA LAJE EM BALANÇO INFINITA ENRIJECIDA) permite inferir que a presença de vigas de bordo, enrijecendo o cantilever, proporciona uma maior eficácia na distribuição dos efeitos de influência gerados pela aplicação da carga concentrada, o que ocasiona a redução dos momentos de picos despertados na direção longitidinal do engaste.

O gráfico da Figura 6 explicita a variação de intensidade de momentos despertados no engaste, a partir da alocação da carga concentrada em diversas posições ao longo do tabuleiro, onde é possível identificar que os valores dos momentos fletores tendem a aumentar a medida que a carga aplicada é afastada da posição incial de origem, até a distância equivalente da seção transversal do cantilever, adotada como $2 \mathrm{~m}$. Vale ressaltar que a aplicação da carga concentrada a uma distância equivalente ao dobro do comprimento transversal do cantilever gera uma mudança na curva de crescimento do momento, onde o mesmo passa a apresentar valores baixos e praticamente desprezíveis, tendendo a zerar. 
Figura 7: Momento de engastamento laje semi-infinita enrijecida (CASO 4).

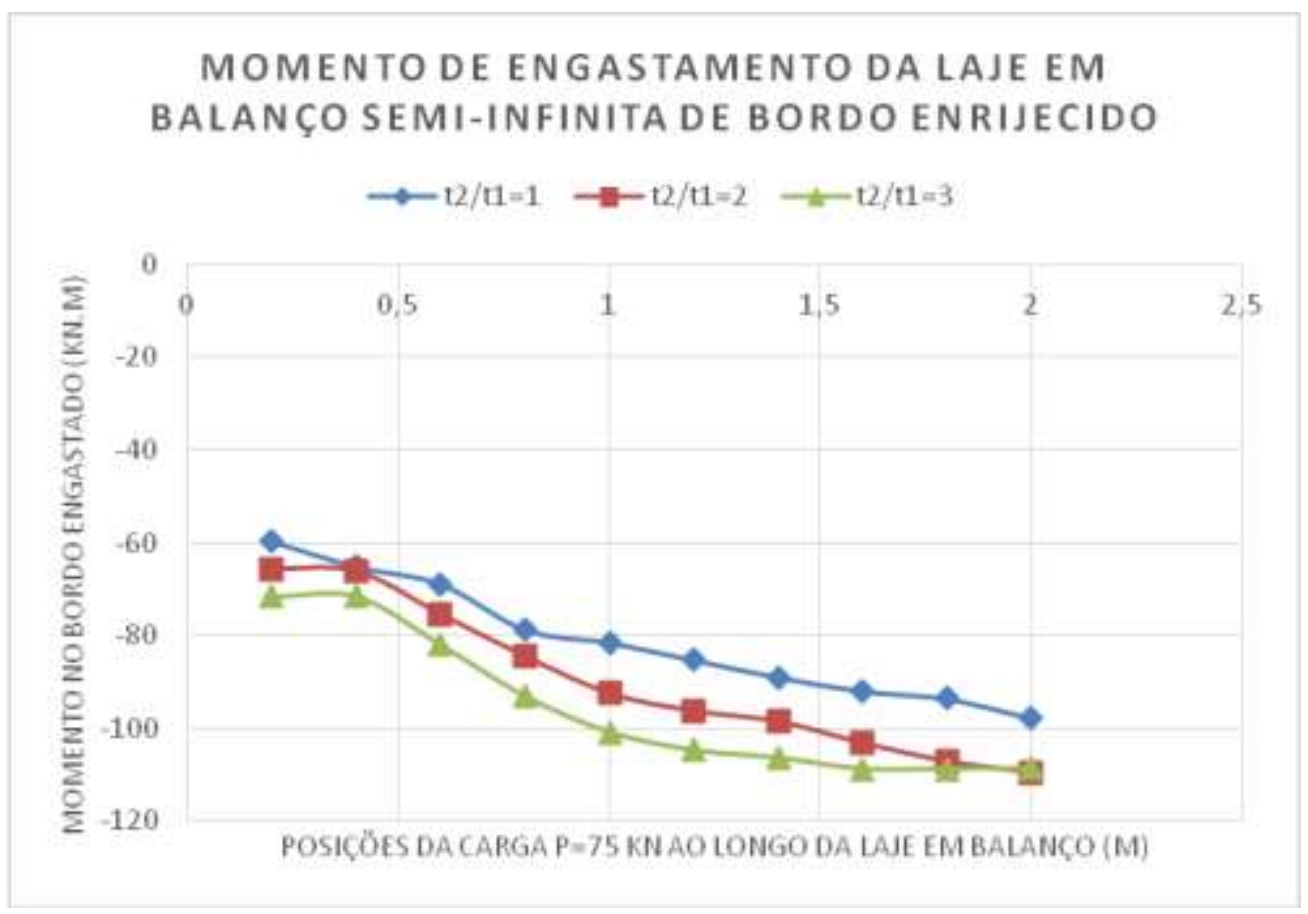

Fonte: Autores.

Na análise do CASO 4 (MÉTODO PARA UMA LAJE EM BALANÇO SEMI-INFINITA ENRIJECIDA), observa-se que as características resultantes da utilização de vigas de bordo, com fins de enrijecimento da estrutura em balanço, apresentam os mesmos benefícios do CASO 3, onde ocorre uma redução da intensidade dos momentos fletores despertados na direção longitudinal da raiz do balanço (bordo engastado), isso ocorre pelo fato do enrijecimento auxiliar na melhor distribuição da região de influência da carga concentrada aplicada no tabuleiro.

Observa-se ainda com base no gráfico da Figura 7 que a apesar de ocorrer a redução dos momentos fletores, quando comparado com o mesmo caso sem enrijecimento do cantilever (CASO 2), a tendência da intensidade dos momentos despertados na direção longitudinal tende a aumentar à medida que a carga aplicada vai se distanciando no ponto de referência.

É importante destacar que a relação da intensidade de momentos fletores, associada a razão das espessuras das lajes em balanço também segue a tendência dos casos anteriores, com ou sem enrijecimento, onde é perceptível que a variação de espessuras tende a influenciar no aumento dos momentos gerados, como apresenta o gráfico com as relações $\mathrm{t}_{2} / \mathrm{t}_{1}$ variando em 1,2 e 3. 
5.3 Análise da utilização de vigas de bordo em lajes em balanço infinitas

Figura 8: Comparativo de eficiência do enrijecimento $t_{2} / t 1=1$.

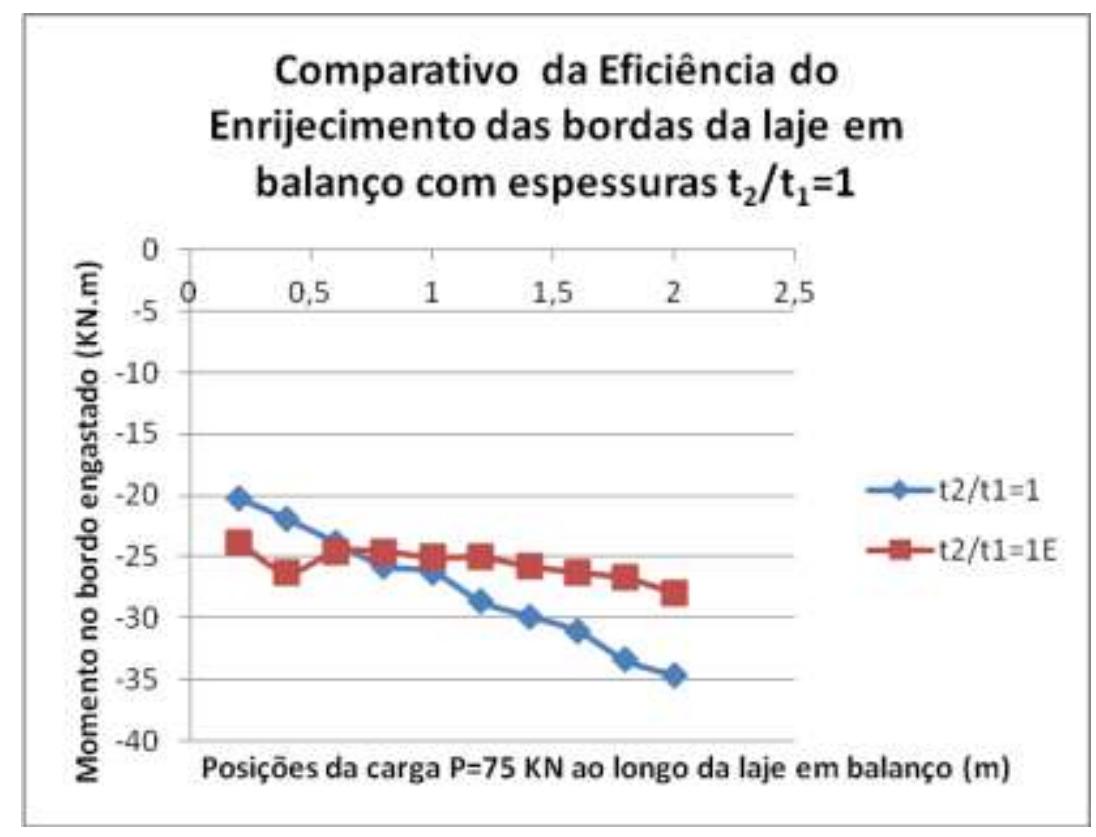

Fonte: Autores.

Figura 9: Comparativo de eficiência do enrijecimento $t_{2} / \mathrm{t} 1=2$.

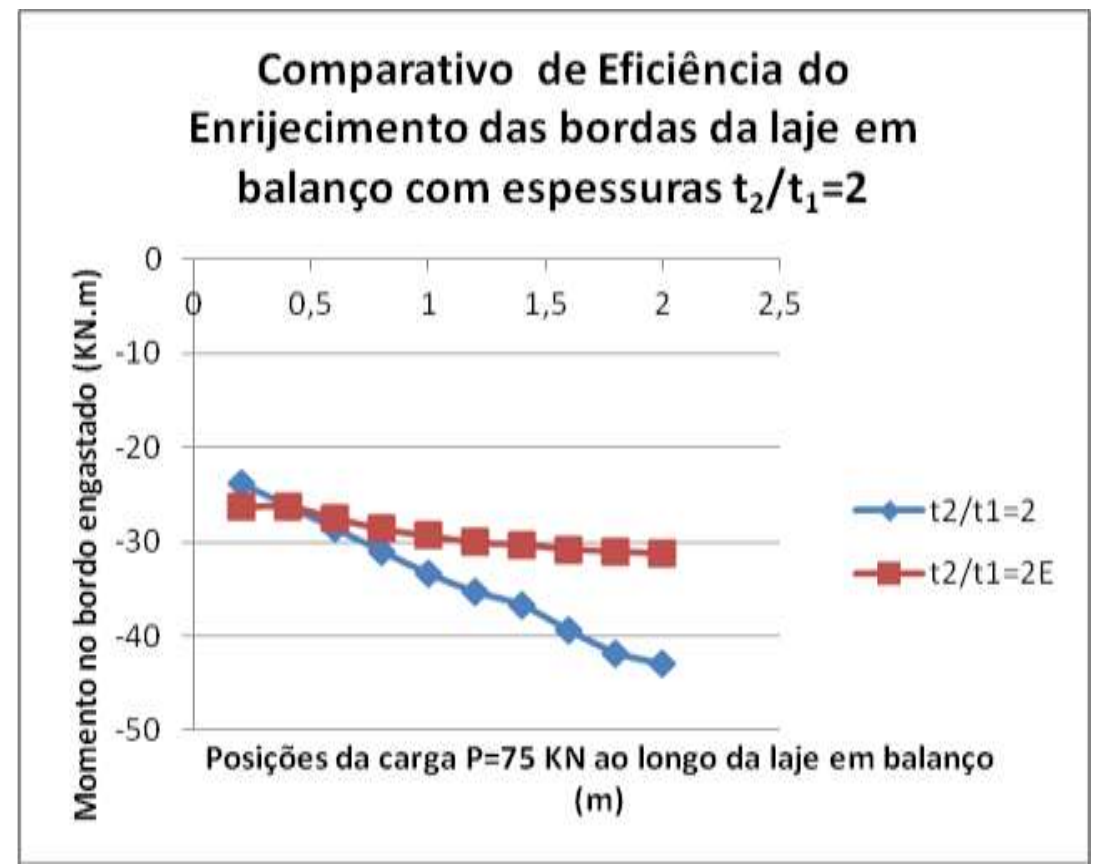

Fonte: Autores. 
Figura 10: Comparativo de eficiência do enrijecimento $t_{2} / t_{1}=3$.

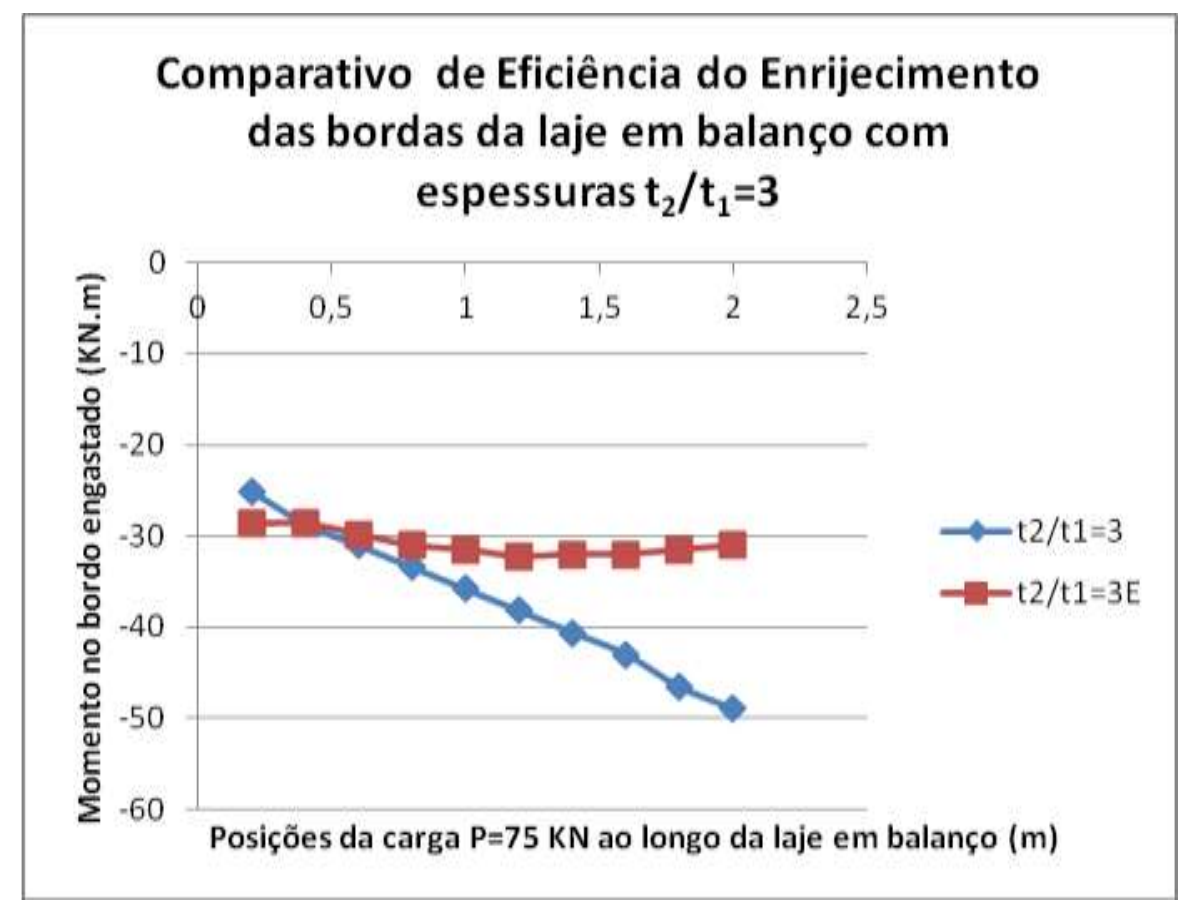

Fonte: Autores.

Conforme apresentado nos gráficos das Figuras 8, 9 e 10 observa-se que a presença de vigas nas bordas das lajes em balanço (cantilever) contribui significativamente para o melhor desempenho da distribuição da carga concentrada ao longo da área do balanço, o que consequentemente gera efeitos benéficos na redução da intensidade de momentos fletores despertados no engaste na direção longitudinal.

No gráfico da Figura 10 podemos constatar que nos casos de espessuras de lajes com razão $t_{2} / t_{1}=3$, os efeitos da presença de vigas de bordo chegam a reduzir a intensidade dos momentos fletores em aproximadamente $40 \%$ à medida que a aplicação da carga concentrada vai se afastando do ponto inicial de referência ao longo do tabuleiro, de modo a despertar valores de momentos fletores maiores na direção longitudinal.

Em observância a Figura 10 percebe-se que a aplicação da carga concentrada na distância inicial, próximo ao ponto de referência, resulta momentos fletores maiores nas lajes infinitas com bordo enrijecido até a distância 0,5 m, onde a partir daí ocorre uma inversão dos valores, os as lajes infinitas sem enrijecimento passam a apresentar valores maiores. 
Tabela 1: Percentual de redução dos momentos fletores.

\begin{tabular}{|c|c|c|c|}
\hline \multicolumn{4}{|c|}{ LAJE EM BALANÇO INFINITA CASO 1 X CASO 3} \\
\hline \multicolumn{4}{|c|}{ PERCENTUAL DE AUMENTO (+) OU REDUÇÃO (-) } \\
\hline \multicolumn{4}{|c|}{ DE MY } \\
\hline Posições da carga & $\mathbf{t} 2 / \mathrm{t} 1=1$ & $\mathbf{t} 2 / \mathbf{t} 1=2$ & $\mathbf{t} 2 / \mathbf{t} 1=3$ \\
\hline 0,2 & $18 \%$ & $10 \%$ & $14 \%$ \\
\hline 0,4 & $20 \%$ & $0 \%$ & $0 \%$ \\
\hline 0,6 & $3 \%$ & $-4 \%$ & $-4 \%$ \\
\hline 0,8 & $-5 \%$ & $-8 \%$ & $-7 \%$ \\
\hline 1 & $-5 \%$ & $-12 \%$ & $-12 \%$ \\
\hline 1,2 & $-13 \%$ & $-15 \%$ & $-16 \%$ \\
\hline 1,4 & $-14 \%$ & $-18 \%$ & $-21 \%$ \\
\hline 1,6 & $-15 \%$ & $-22 \%$ & $-26 \%$ \\
\hline 1,8 & $-20 \%$ & $-26 \%$ & $-32 \%$ \\
\hline 2 & $-19 \%$ & $-27 \%$ & $-37 \%$ \\
\hline MÉDIA & $-5 \%$ & $-12 \%$ & $-14 \%$ \\
\hline
\end{tabular}

Fonte: Autores.

A Tabela 1 apresenta o comparativo em percentual do aumento ou redução da intensidade dos momentos fletores nas lajes infinitas com ou sem enrijecimento das bordas (CASO 1 X CASO 2). Observam-se nas posições iniciais de aplicação de carga concentrada na laje em balanço que a presença de vigas de borda não apresenta tantas vantagens, porém, a partir de uma distância significativa de aplicação de carga em relação ao ponto de referência inicial, é perceptível a análise da queda da intensidade de momentos fletores nas lajes enrijecidas, quando comparadas as não enrijecidas.

Cumpre destacar que as vantagens maiores da utilização de vigas de bordas em lajes infinitas ocorrem nas razões de espessuras $t_{2} / t_{1}>1$, como é o caso $t_{2} / t_{1}=3$, onde a média de redução da intensidade de momentos fletores despertados na direção longitudinal chega a $14 \%$, e consequentemente menores problemas relacionados ao surgimento de fissuras que reduzem a rigidez à flexão da peça estrutural.

\section{Conclusão}

Com base nos resultados apurados, pode-se perceber que na comparação de lajes em balanço infinitas não enrijecidas e infinitas enrijecidas a presença de viga de borda reduz a magnitude dos momentos despertados no engaste do balanço.

Percebe-se que o mesmo acontece nas lajes semi-infinitas não enrijecidas e enrijecidas, onde podemos verificar que os momentos transversais tendem a reduzir na direção longitudinal do engaste com a utilização de vigas de bordo.

Esse fato ocorre devido à ação das vigas de bordo que auxiliam na distribuição da carga concentrada aplicada ao longo da laje em diversas posições da seção transversal, fazendo com que os momentos despertados no balanço sejam menores, quando comparados com as mesmas lajes, porém, sem a presença do enrijecimento.

Vale destacar que a razão entre as espessuras das lajes influencia diretamente na intensidade dos momentos despertados no bordo engastado, onde claramente percebe-se que a razão das espessuras é diretamente proporcional a intensidade dos momentos gerados na raiz do cantilever. 
Cumpre ressaltar que as posições de aplicações da carga concentrada ao longo da seção transversal também contribuem para a propagação dos momentos despertados no engaste, à medida que a distância da carga aplicada aumenta em relação à raiz do cantilever, constata-se que a intensidade do momento transversal despertado tende a aumentar.

A partir dos modelos analisados infere-se que a associação de vigas de bordo em lajes em balanço, com variação maior de espessuras apresenta maior eficiência na redução dos momentos transversais máximos despertados na direção longitudinal, quando compradas com as outras razões de espessuras.

Por fim, como proposta de trabalhos e pesquisas futuras, recomenda-se a elaboração de uma análise comparativa do modelo matemático estudado nesse trabalho, com um modelo numérico, utilizando software de análise estrutural, baseado no método de elementos finitos (MEF), com a finalidade de comparação da precisão de resultados de cada modelo.

\section{Referências}

Associação Brasileira de Normas Técnicas. ABNT NBR 7188 (2013). Carga móvel rodoviária e de pedestres em pontes, viadutos, passarelas e outras estruturas.

Associação Brasileira de Normas Técnicas, ABNT NBR 7187 (2003). Projeto de pontes de concreto armado e de concreto protendido.

Bakht, B. \& Mufti, A. (2015). Bridges analysis, design, structural health monitoring, and rehabilitation. Springer.

Bakht, B. \& Jaeger, L. G. (1985). Bridge analysis simplified, McGraw-Hill Book Company.

Bakht B. \& Holland, D. A. (1976) A manual method for the elastic analysis of wide cantilever slabs of linearly varying thickness. Can J Civ Eng 3(4):523-530

Bakht. B., Aziz, T. S., \& Bantusevicius, K. F. (1979). Manual analysis of cantilever slabs of semi-infinite width. Can J Civ Eng 6(2):227-231

Cunha, A. J. P. \& Souza, V. C. M. (1994). Lajes em concreto armado e protendido. EDUFF.

Cusens, A. R., \& Pama, R. P (1975). Bridge deck analysis. John Wiley \& Sons.

El Debs, M. K., Malite, M., Takeya, T., Munair Neto, J.\& Hanai, J.B. (2001). Análise das consequências do Tráfego de combinações de veículos de carga ( cves) sobre as Pontes da rede viária sob jurisdição do DER-SP. Departamento de Estradas de Rodagem do Estado de São Paulo, Relatório Técnico, Minerva.

Leonhardt, F.(1982). Brucken-Bridges. The Architetural Press.

Meireles, A. P. C. Levantamento e Diagnóstico de uma ponte metálica antiga. 2010. 74p. Dissertação de Mestrado (Mestrado em Engenharia Civil) Departamento de Engenharia Civil, Faculdade de Engenharia da Universdade do Porto, Porto - Portugal.

Mendes, L. C.(2003). Pontes. Editora da Universidade Federal Fluminense.

Marchetti, O. (2018). Pontes de concreto armado. Blucher.

Munoz, L. J. V.(2020). Bridge Overhangs Slabs with Edge Beams. 125p. Doctoral Thesis (Doctoral Thesis in Structural Engineering and Bridges) - KTH Royal Institute of Technology, KTH, Stockholm.

O’Connor, Daniel S. (1991) - La gestion de puentes en Estados Unidos - Simpósio Nacional sobre conservacion, rehabilitacion y gestion de puentes, Madrid.

O’Connor, C. (1976). Pontes-superestruturas. Livros Técnicos e Científicos.

Pfeil, Walter. (1979). Pontes em Concreto Armado. Livros Técnicos e Científicos Editora S/A.

PFEIL, Walter. (1983). Pontes: Curso Básico - Editora Campus Ltda.

Quiroga, A. F. S. (1983). Cálculo de Estructuras de Puentes de Hormigon. Editorial Rueda.

Reissen, K. \& Hegger, J. 2015. Experimental investigations on the shear capacity of RC cantilever bridge deck slabs under concentrated loads - Influences of moment-shear ratio and an inclined compression zone. 16th European Bridge Conference, Edinburgh, Scotland

Rowe, R. E. (1972). Concrete bridge design. Science Publishers LTD.

Silva, S. C.(2016). Análise paramétrica de superestrutura de ponte em viga contínua. 315p. Trabalho de Conclusão de curso (Graduação em Engenharia Civil) - Escola Politécnica, UFRJ, Rio de Janeiro.

Tardivo, F. G. (2014). Estudo de Esquemas estruturais e modelagem de tabuleiros de pontes esconsas. 162p. Dissertação de mestrado ( Mestrado em Engenharia Civil) - Escola Politécnica da Universidade de São Paulo, USP, São Paulo.

Vitório, A.(2002). Pontes Rodoviárias. CREA-PE. 